Erratum

\title{
Erratum to "Major Histocompatibility Complex I Mediates Immunological Tolerance of the Trophoblast during Pregnancy and May Mediate Rejection during Parturition"
}

\author{
Anna Rapacz-Leonard, Małgorzata Dąbrowska, and Tomasz Janowski \\ Department of Animal Reproduction with Clinic, Faculty of Veterinary Medicine, University of Warmia and Mazury, \\ Ulica Oczapowskiego 14, 10-719 Olsztyn, Poland \\ Correspondence should be addressed to Anna Rapacz-Leonard; anna.rapacz@uwm.edu.pl \\ Received 24 June 2014; Accepted 7 July 2014; Published 23 July 2014 \\ Copyright (C) 2014 Anna Rapacz-Leonard et al. This is an open access article distributed under the Creative Commons Attribution \\ License, which permits unrestricted use, distribution, and reproduction in any medium, provided the original work is properly \\ cited.
}

In the paper, two inaccuracies have been found.

The first inaccuracy is in Section 2.2 on page 3 (in the pdf) in the following sentence: "These are classical MHC I that induce inflammation and their expression of immune rejection might lead to recognition by cytotoxic $\mathrm{T}$ lymphocytes and immune rejection."

It should be without "of immune rejection."

The second inaccuracy is in Section 3.4.1 on page 7 in the following sentence: "These lymphocytes are thought to protect the pregnancy against external antigens and to support trophoblast growth by secreting IL-8, which promotes trophoblast invasion."

It is not "external antigens" but "pathogens."

We apologize for this oversight and for any confusion that it has caused. 


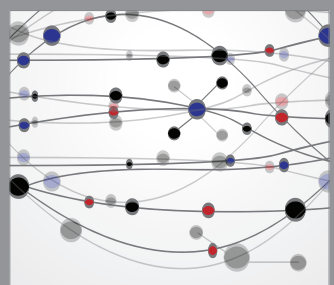

The Scientific World Journal
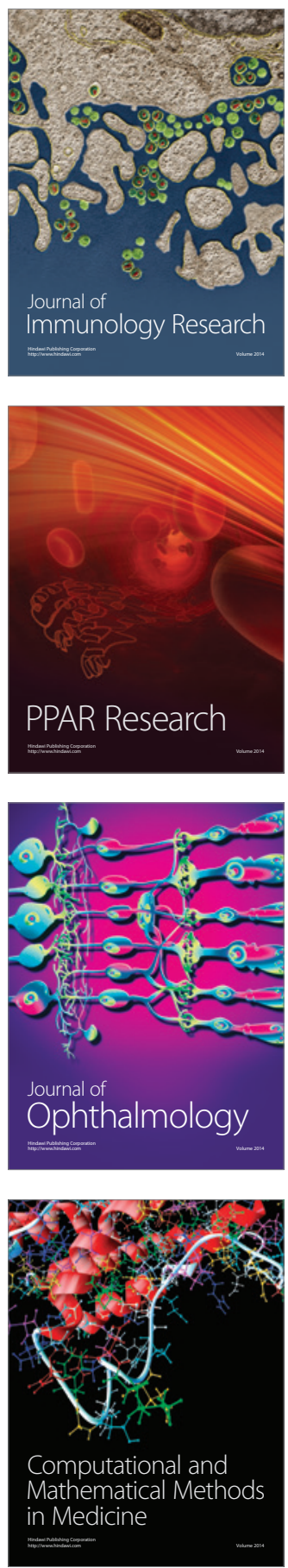

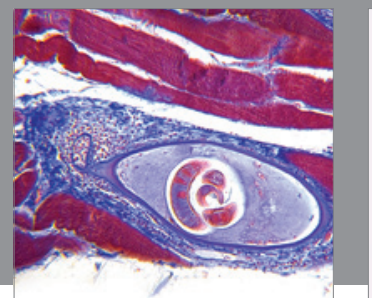

Gastroenterology

Research and Practice
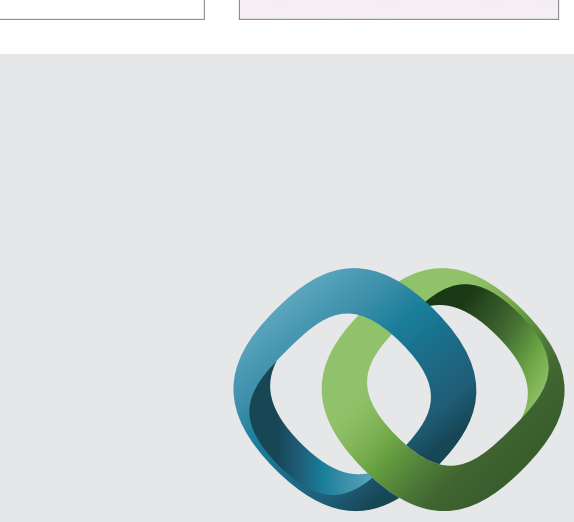

\section{Hindawi}

Submit your manuscripts at

http://www.hindawi.com
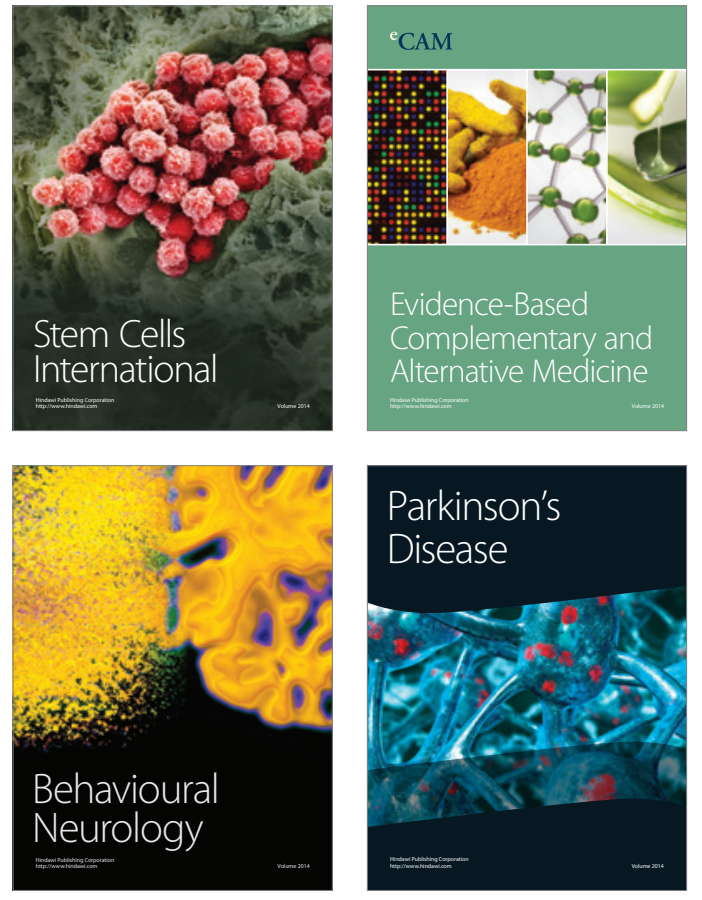
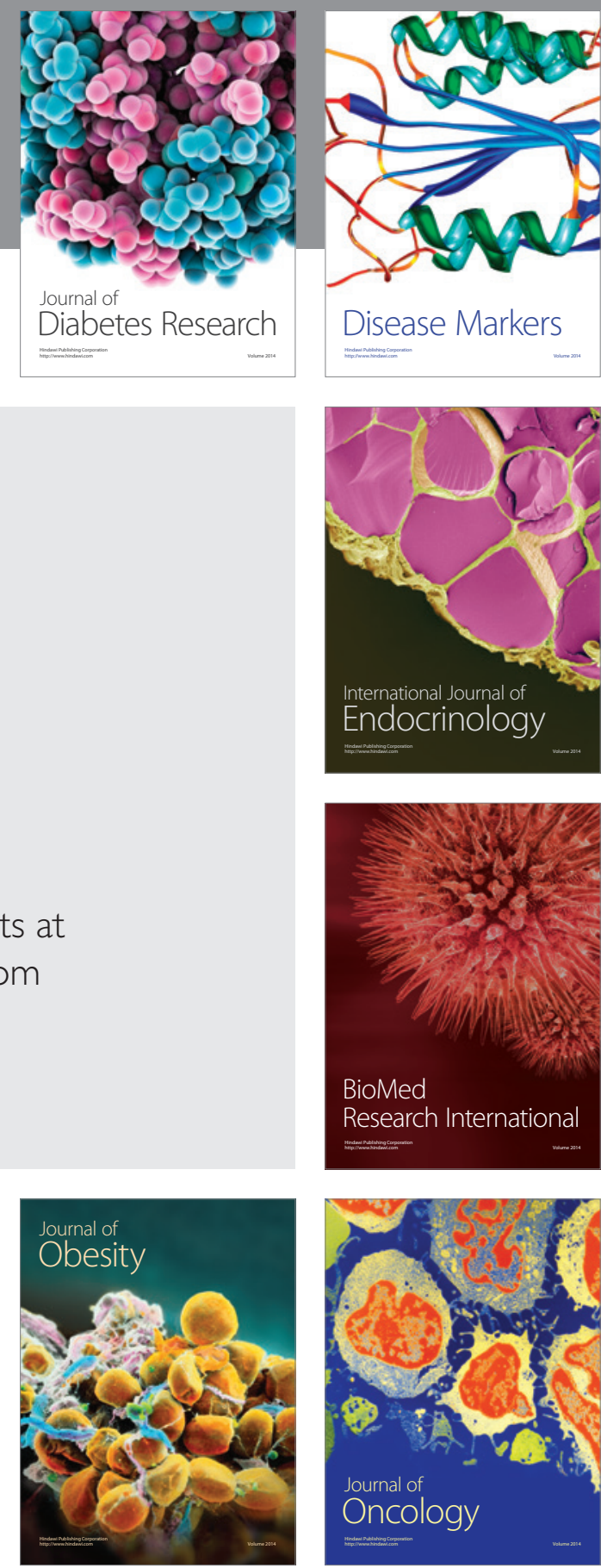

Disease Markers
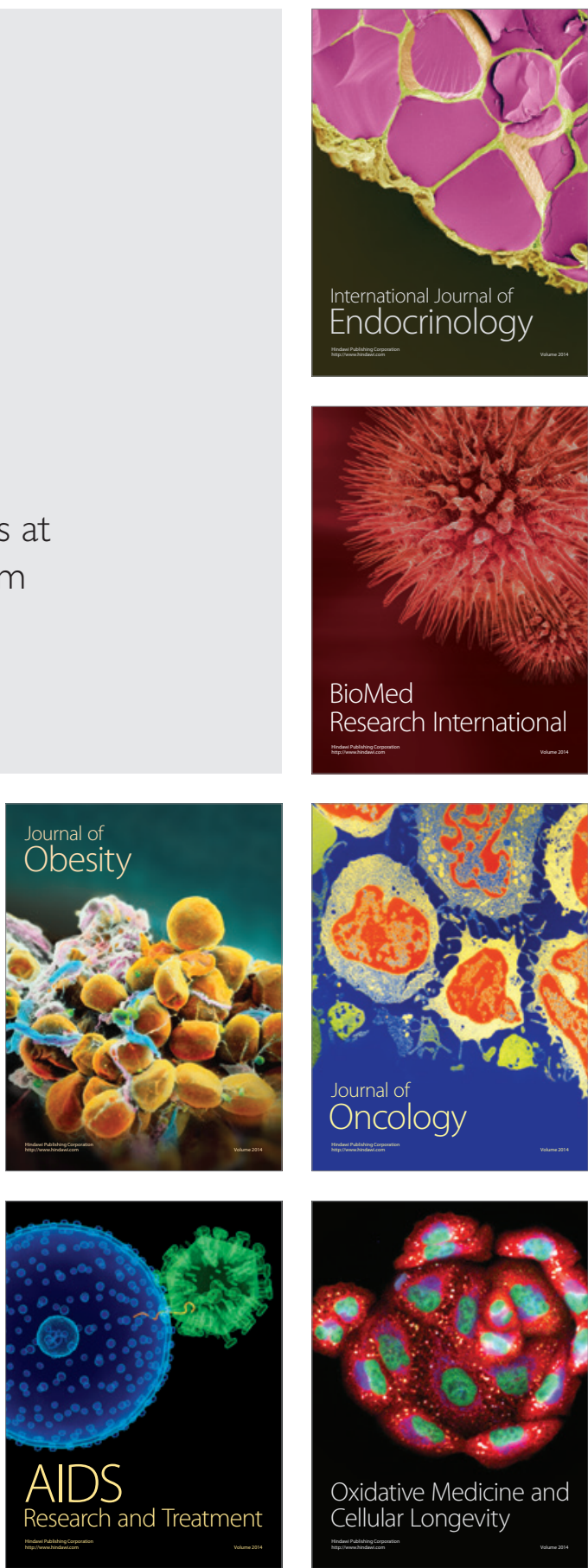